\title{
HEAD AND NECK
}

\section{Pilot study on microvascular anastomosis: performance and future educational prospects}

\section{Studio pilota sulle microanastomosi vascolari: risultati a confronto e prospettive didattiche future}

\author{
G. Berretti', G. Colletti², G. Parrinello ${ }^{1}$, A. lavarone ${ }^{1}$, P. Vannucchi' ${ }^{1}$, A. Deganello ${ }^{1}$ \\ ${ }^{1}$ Department of Surgery and Translational Medicine, University of Florence, Italy; ${ }^{2}$ Maxillofacial Surgery, San Paolo \\ Hospital, University of Milan, Italy
}

\begin{abstract}
SUMMARY
The introduction of microvascular free flaps has revolutionised modern reconstructive surgery. Unfortunately, access to training opportunities at standardised training courses is limited and expensive. We designed a pilot study on microvascular anastomoses with the aim of verifying if a short course, easily reproducible, could transmit microvascular skills to participants; if the chosen pre-test was predictive of final performance; and if age could influence the outcome. A total of 30 participants (10 students, 10 residents and 10 surgeons) without any previous microvascular experience were instructed and tested during a single 3 to 5 hour course. The two microanastomoses evaluated were the first ever performed by each participant. More than the half of the cohort was able to produce both patent microanastomoses in less than 2 hours; two-thirds of the attempted microanastomoses were patent. The pretest predicted decent scores from poor performances with a sensitivity of $61.5 \%$, specificity of $100 \%$, positive predictive value of $100 \%$ and negative predictive value of $40 \%$. Students and residents obtained significantly higher scores than surgeons. Since our course model is short, cost-effective and highly reproducible, it could be introduced and implemented anywhere as an educational prospect for preselecting young residents showing talent and natural predisposition and having ambitions towards microvascular reconstructive surgery.
\end{abstract}

KEY WORDS: Microvascular anastomosis • Free flap $\bullet$ Microvascular training • Surgical skills • Education

\section{RIASSUNTO}

L'introduzione dei lembi liberi microvascolari ha rivoluzionato la moderna chirurgia ricostruttiva. Purtroppo, l'accesso a corsi specifci e intensivi è attualmente limitato e costoso. Abbiamo organizzato uno studio pilota sulle microanastomosi vascolari con lo scopo di verificare: se un corso economico e facilmente riproducibile potesse trasmettere ai partecipanti delle abilità microchirurgiche di base; se il test preliminare scelto fosse predittivo dei risultati finali; e se l'età potesse essere un fattore in grado di influenzare la performance. Sono stati selezionati un numero complessivo di 30 partecipanti (10 studenti, 10 specializzandi e 10 chirurghi), senza nessuna precedente esperienza microchirurgica, ai quali è stato proposto un corso della durata di 3-5 ore. Le anastomosi conclusive, sottoposte a valutazione, sono state le prime realizzate da ciascun partecipante. Più della metà degli individui testati è stata in grado di confezionare entrambe le microanasromosi funzionanti e in un tempo inferiore alle 2 ore; nel complesso due terzi delle microanastomisi realizzate erano pervie. Il test preliminare è stato in grado di predire risultati finali buoni rispetto a risultati finali scarsi con una sensibilità del $61 \%$, una specificità del $100 \%$, un valore predittivo positivo pari al $100 \%$ ed un valore predittivo negativo del $40 \%$. Studenti e specializzandi hanno ottenuto punteggi significativamente migliori rispetto ai chirurghi. Dato che il corso da noi proposto è breve, dai costi contenuti e facilmente riproducibile, riteniamo possa essere facilmente implementato in altre strutture al fine di selezionare giovani specializzandi dotati di talento con una naturale predisposizione per la microchirurgia, e che dimostrino interesse ed ambizione nel campo della chirurgia ricostruttiva.

PAROLE CHIAVE: Anastomosi microvascolari $\bullet$ Lembi liberi $\bullet$ Esercitazioni microvascolari $\bullet$ Abilità chirurgiche $\bullet$ Apprendimento

Acta Otorhinolaryngol Ital 2018;38:304-309

\section{Introduction}

In the early years of the 20th century, Carrel codified the triangulation technique obtaining functioning vascular anastomosis ${ }^{1-3}$ to investigate the feasibility of organ transplantation.

Otolaryngologists were the first physicians to use microsurgical techniques. In 1921, the microscope was used for 
the first time in ear surgery by a Swedish otologist, Carl Olof Nylen ${ }^{34}$, the next year Gunnar Holmgren replaced the first monocular microscope with a binocular one ${ }^{4}$. The application of the microscope to vascular anastomosis allowed the first successful microvascular transfer of a jejunal interposition flap in $1959^{5}$.

The introduction of microvascular free flaps revolutionised the surgical treatment of head and neck tumours and represents one of the major advancements in the management of these neoplasms. Microsurgery requires considerable practice before any attempt is made at clinical application. Live animals represent the ideal training medium; however, unlimited access to the animal laboratory is not always possible ${ }^{6}$. In such situations, segments of fresh human placenta or other surrogates such as pig coronaries or chicken wing vessels can provide adequate specimens for microsurgical practice.

At our tertiary referral academic hospital, to date, no specific microvascular training program is available for students, residents or surgeons, and no specific financial support is provided for those who intend to build up these skills attending national and/or international microvascular courses. This situation is diffuse all over the country, and this aspect penalises even more youngest surgeons with access to limited economic resources, despite the fact that it seems that age in itself plays an important role in the abrupt of the learning process. In fact, a study comparing the results of microsurgical education after the completion of a comprehensive microsurgical course program between students and surgeons demonstrated that the students achieved higher scores, with a significant better performance in tissue handling ${ }^{7}$.

We designed a pilot study on microvascular anastomoses with the aim of verifying if even a simple short course, easily reproducible, could transmit microvascular skills to participants; if the chosen pre-test was predictive of the final performance; and if age could influence the outcome.

\section{Materials and methods}

From April to September 2016, 30 voluntary participants were enrolled and tested in our pilot study.

\section{Population}

Inclusion criteria were: motivation and willingness to participate, complete lack of previous microvascular experience, age in concordance with the professional position. The cohort was formed of 3 groups;

- Group 1 (G1): 10 students attending the sixth (last) year of medical school, all aged under 28 years (mean
24.8), with no surgical experience; 7 expressed ambition to a career in a surgical specialty.

- Group 2 (G2): 10 residents in surgical disciplines (5 in otolaryngology, 3 in general surgery, 1 in vascular surgery, and 1 in orthopaedic surgery), aged between 28 and 35 years (mean 29.8), usually attending macroscopic surgery as second operator, sometimes as first operator under supervision, but none with specific experience on microvascular anastomosis or microscopic ear surgery.

- Group 3 (G3): 10 surgeons (8 otolaryngologists, 1 vascular surgeon, and 1 maxillofacial surgeon) aged over 35 years (mean 51.5) usually performing macroscopic surgery as first operator. The 8 otolaryngologists were skilled in microscopic laryngeal surgery, but none had any experience in microvascular anastomosis or microscopic ear surgery.

\section{Microanastomosis course}

Each participant was instructed and then individually tested in one session that varied between 3 to 5 hours; a schematic representation of the structure of the course is displayed in Figure 1.

A brief theoretical introduction to experimental microsurgery was provided: correct posture, use of the microscope, handling of microinstruments, end to end microsuture technique for artery and vein, exercises on a macroscopic model for microscopic arterial and venous microanastomoses and tasks required.

A preliminary pre-test was initially administrated, namely the so-called 'round-the-clock' training model ${ }^{8}$, which proved to be an inexpensive and readily available valid tool to provide instant assessment of the individual microsurgical predisposition (Fig. 2). Participants were asked to pass a $9 / 0$ nylon microsuture needle through the needle

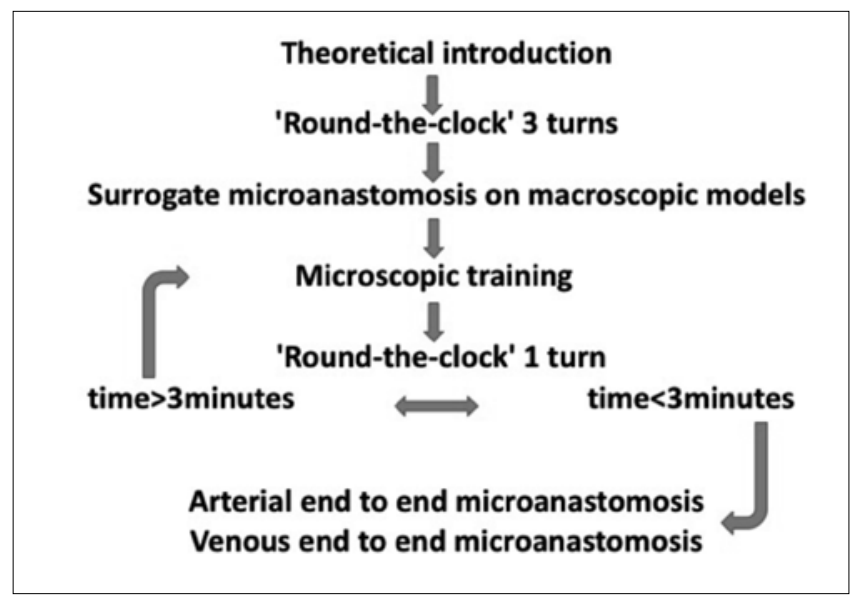

Fig. 1. Schematic representation of the course. 


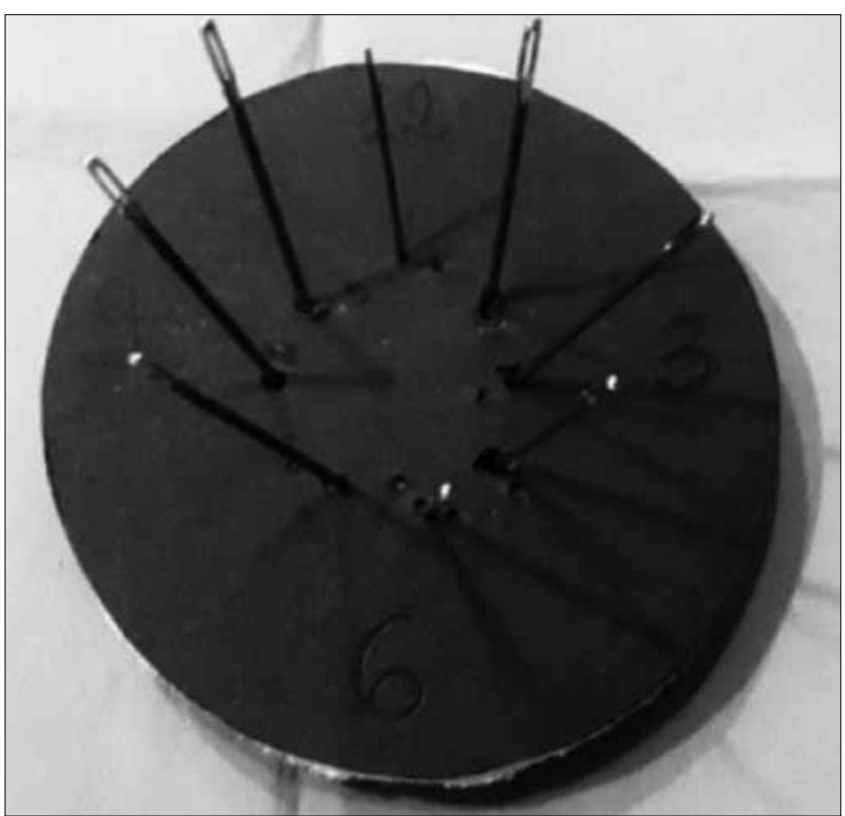

Fig. 2. The 'round-the-clock' test, each run had to be completed clockwise under microscopic magnification at $6 \mathrm{X}$ using $9 / 0$ suture.

eyes of nine sewing needles planted on a rigid support, each run had to be completed clockwise; the time of each run for 3 consecutive runs was recorded, without considering steadiness or handling abilities.

Participants were then familiarised with microsuture techniques for end-to-end arterial and venous anastomoses using a macroscopic model: the artery surrogate was a silicon tube, since the lumen is maintained; the vein surrogate was a finger glove, since lumen tend to collapse. When performing surrogate microanastomoses, the same handling rules and same techniques required for true microanastomoses had to be respected, with the only difference of working without the microscope and using a $5 / 0$ suture. For the surrogate arterial microanastomosis, the triangulation technique with interrupted sutures was used; for the surrogate venous anastomosis, after placing the first two stay sutures at 2 o'clock and 10 o'clock, the superior $180^{\circ}$ were sutured, and then the inferior $180^{\circ}$. During the surrogate microanastomoses the instructor surveyed the participant, pointing out and explaining all handling errors according to the technical requirements previously explained in the theoretical introduction.

The next step was microscopic training on an animal model; we used one half rooster per participant since it provided good quality vessels, very similar in diameter to those encountered for microvascular head and neck reconstructions, with average diameter of $3 \mathrm{~mm}$ (range $2.5 \mathrm{~mm}-3.5 \mathrm{~mm}$ ).
Participants were free to familiarise themselves with microsutures using the sciatic nerve or other tissues, but not vessels; no time restrictions were given for this training, while the instructor provided constant feedback on handling and errors, by pointing out: incorrect posture, incorrect use of the microscope, incorrect microinstrument handling, incorrect tissue handling, incorrect needle handling and needle damage, unwanted perforations, asymmetric knots placement, incorrect knots tying. All this followed the requirements listed by the Northwestern Objective Microanastomosis Assessment Tool (NOMAT) ${ }^{9}$.

After microscopic training, participants performed a fourth run at the 'round-the-clock' test, if the exercise was completed in less than 3 minutes (this cut-off was chosen considering four times the mean time recorded by the experienced microsurgeon, $\mathrm{AD}$ ) they could move forward to perform the microanastomoses, otherwise they had to return to the microscopic training before re-attempting another 'round-the-clock' run until the threshold of 3 minutes was satisfied. Times recorded on this fourth run at the 'round-the-clock' test were considered good when below 2 minutes, intermediate when between 2 and 3 minutes, and poor when above 3 minutes.

Microvascular end-to-end arterial anastomosis using 8/0 nylon interrupted sutures was performed first, then the venous end-to-end anastomosis was performed. Participants had one-hour to complete each microanastomosis or to complete at least the minimal-task. During the microanastomoses participants were surveyed, but no feedback on errors and no suggestions were provided by the instructor, who, instead, took note and counted all errors.

All macro-microsurgical instruments were propriety of the senior author (AD), all animal models were bought by the first author (GB) at her own expense; the macro-micro surgical suture materials were outdated and ready to be discarded.

\section{Scoring system}

Arterial and venous microanastomoses were separately evaluated. The minimal-task for the artery was considered to be the correct placement of the first 3 stay sutures and this was awarded with 50 points, the minimal-task for the vein was the correct suture of the superior $180^{\circ}$, for which 50 points were awarded. Zero points were scored in case of inability/incorrect placement of the first 3 stay sutures on the arterial microanastomosis, inability/incorrect suture of the superior venous wall, or in case of minimal-task resulting in lumen obliteration. If the minimal-task was met, the participant could move forward to complete the microanastomosis as much as possible within the one-hour time limit. The time to complete each microanastomosis was re- 
corded, and microanastomoses were evaluated in terms of patency and continence, 100 points were awarded if the microanastomosis was patent and continent, 95 points if the microanastomosis was patent but leaking if one extra stitch was needed and 90 points if two extra stitches were needed. In case three or more stitches were required to restore continence, or if the microanastomosis was not patent, the score was 50 points considering only achievement of the minimal-task. At the final score 2 points were deducted for each incorrect gesture performed during the microanastomosis.

Global (arterial + venous) scores above 160 were considered high, scores between 100 and 160 were considered intermediate and scores below 100 were considered low.

Times recorded for the fourth run at the 'round-the-clock' test were correlated with the microanastomoses global scores.

\section{Statistical analysis}

Differences between groups were tested with ANOVA; the variables, all continuous, were expressed as mean values and standard deviation, and were compared between two different groups with the t-Student test: $p$ values less than 0.05 were considered statistically significant.

\section{Results}

Times (minutes' and seconds") of the first, second, third and fourth run at the 'round-the-clock' are shown in Table I; the analysis showed a significant difference for the fourth round between $\mathrm{G} 1$ and G2 vs. G3 ( $p=0.025)$.

Mean arterial and venous microanastomoses scores are shown in Table II.

Comparison of the global (arterial + venous) performance between groups showed a significant difference between G1 vs. $\mathrm{G} 3(\mathrm{p}=0.0010)$ and between $\mathrm{G} 2$ vs. $\mathrm{G} 3(\mathrm{p}=0.0013)$, indicating a better performance for students and residents compared to surgeons, while no differences were seen between students and residents $(p=0.47)$, Figure 3 .

As already stated, all participants had to complete each microanastomosis within a maximum time limit of 1 hour. The mean arterial and venous microanastomoses times were, respectively, 56 and 51 minutes for G1, 48 and 52 minutes for $\mathrm{G} 2$ and 52 and 52 minutes for $\mathrm{G} 3$.

The 3 minute cut-off time on the fourth run at the 'roundthe-clock' test was able to predict good and intermediate microanastomoses global scores from poor performances with a sensitivity of $61.5 \%$ and a specificity of $100 \%$; the positive predictive value was $100 \%$ and the negative predictive value was $40 \%$.
Table I. Results at 'round-the-clock' test.

\begin{tabular}{lcccc} 
& First run & Second run & Third run & Fourth run \\
G1 & $8^{\prime} 38^{\prime \prime}$ & $5^{\prime} 33^{\prime \prime}$ & $4^{\prime} 11^{\prime \prime}$ & $2^{\prime} 41^{\prime \prime}$ \\
G 2 & $7^{\prime}$ & $4^{\prime} 59^{\prime \prime}$ & $4^{\prime} 22^{\prime \prime}$ & 2 '35" \\
G 3 & $12^{\prime}$ & $8^{\prime} 11^{\prime \prime}$ & $5^{\prime} 5^{\prime \prime}$ & $3^{\prime} 38^{\prime \prime}$ \\
\hline
\end{tabular}

Table II. Mean scores of arterial and venous microanastomoses.

\begin{tabular}{lcc} 
& ARTERY & VEIN \\
G 1 & $82.8($ SD 21.66) & $87.5($ SD 15.62) \\
G 2 & $78($ SD 31.10) & $75.7(31.68)$ \\
G 3 & 56.9 (SD 42.04) & 45.1 (SD 38.45) \\
\hline
\end{tabular}

SD: standard deviation

\section{Discussion}

The surgeon's experience is a critical factor influencing the outcomes of microvascular reconstructions, and the success rate in experienced hands is usually above $95 \%{ }^{10-12}$. However, a study on the first year of clinical experience of three microvascular head and neck surgeons yielded a success rate of $97.5 \%$, showing that well-trained junior microvascular surgeons can achieve survival rates comparable with those of experts ${ }^{12}$.

Lascar et al. compared the patency rates obtained by residents in plastic surgery with different microsurgical experience, varying from residents of the first year with no microsurgical experience to residents of the sixth year with considerable experimental and clinical microsurgical experience. A proportional narrowing of outcome differences among groups was seen with the increase in number of microanastomoses performed by the less experienced ones, until no outcome differences were recorded after 52 microanastomosis ${ }^{13}$, demonstrating that constant intense training is necessary to achieve high standards. In this view, a 3 to 5 hour course is usually considered much too short for formal microsurgery training. However, the principal philosophy of the study was not focused on offering intensive microsurgical education, but rather on implementing a highly accessible and inexpensive microsurgery facility. Our course was effective in transmitting a microvascular starting point, with the aim of identifying the youngest and most talented physicians for future advancements.

The results indicate that even a simple, rapid, highly reproducible and low-cost course can effectively transmit microvascular skills to participants. In fact, more than the half of the cohort ( 7 students, 7 residents and 3 surgeons) was able to produce, in less than 2 hours, both arterial and venous microanastomoses functioning. Furthermore, two-thirds 


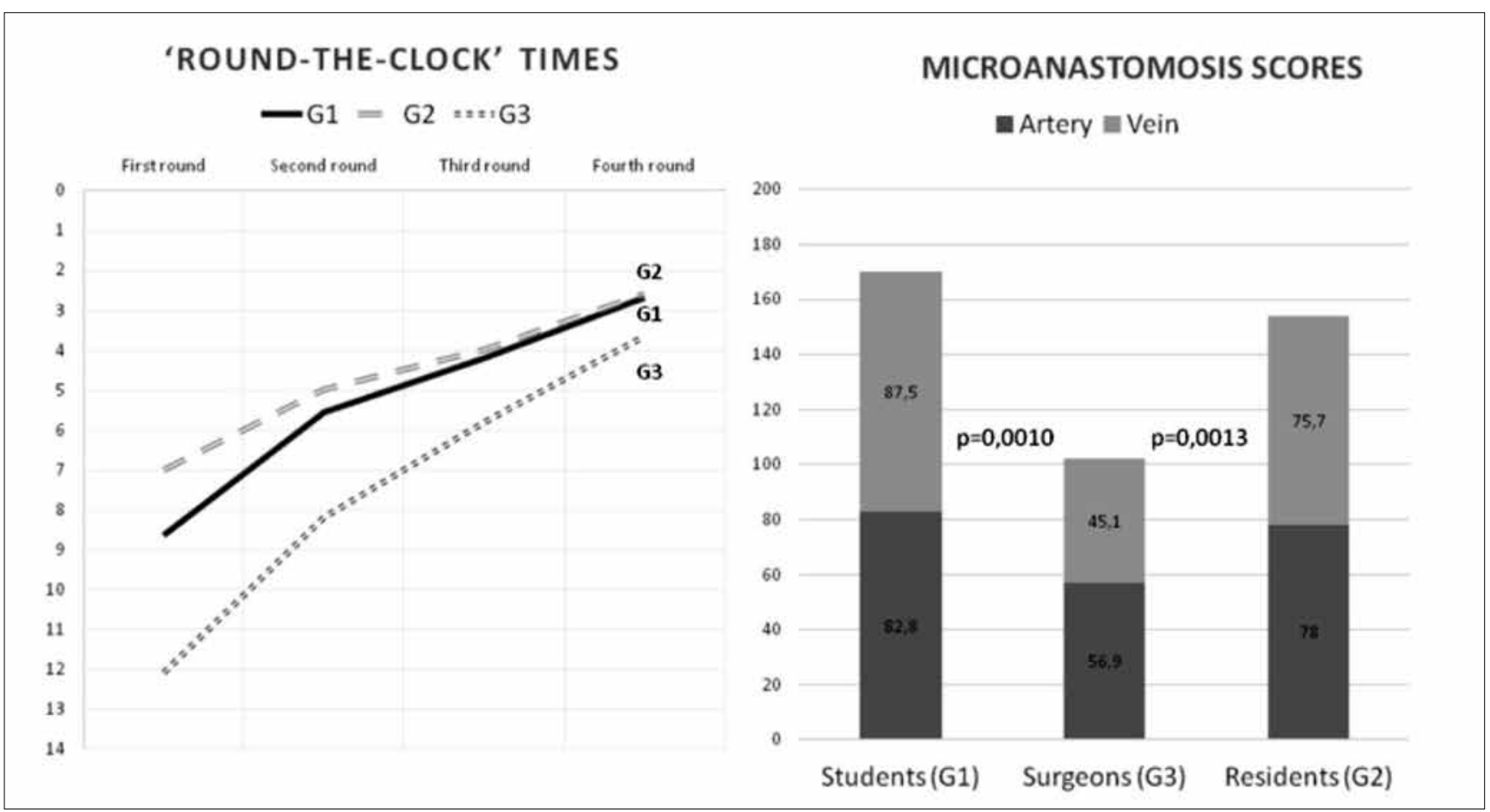

Fig. 3. Performances of the three groups at the pretest and microanastomosis.

(39 of 60) of the attempted microanastomoses were patent, and among these, 20 were also perfectly continent, while in 17 cases one extra stitch was needed to stop leakage, and in 2 cases 2 stitches were needed. The time limit of 1 hour per microanastomosis was set because from a clinical point of view two hours is an acceptable ischaemia time for most fascio-cutaneous and osteo-cutaneous free flaps.

These results are remarkable considering that none of the subjects possessed any microvascular experience, no one had attended other microvascular courses before and the two microanastomoses considered were the first ever performed by all participants. Our evaluation system is not validated, but we preferred to design a scoring system that was more focused on final microanastomosis evaluation rather than homogeneously evaluating the ongoing performance during the microanastomosis. We felt that the NOMAT system was more suitable for monitoring the evolution in building up the global microvascular experience within more structured courses, rather than assessing the results of a single attempt in a mini-course.

The 'round-the-clock' test with a 3 minute cut-off time confirmed to be an effective exercise and a powerful predictive tool with $100 \%$ specificity and positive predictive values, which means that it could be effectively used to preselect subjects who almost surely will perform well. In fact, none of the 16 subjects who completed the fourth run in less than 3 minutes had a poor microanastomosis global score: 13 had good performance ( 5 students, 6 residents, 2 surgeons) and 3 an intermediate performance (2 students and 1 resident).

Students and residents obtained significantly higher scores than surgeons. This seems to confirm that age is a real and crucial factor for acquisition of microvascular skills: 3 surgeons were unable to complete the minimal task and only 3 produced both functioning microanastomoses. Therefore, our data indicate that age seems to be more determinant than surgical background experience for the acquisition of microvascular skills, and this is paralleled by the finding that surgeons were more prone to errors than the younger participants.

For all participants, the arterial microanastomosis was performed first and the venous anastomosis was performed subsequently. Venous microanastomosis is recognised to be technically more difficult than an arterial one, mainly because the vessel lumen tend to collapse, and beginners are expected to perform better with less demanding duties; G1, instead, was the only group with venous scores higher than the arterial ones. This data is interesting: students demonstrated the ability to keep on learning and perfecting the technique as 'on the job' training. When performing a venous anastomosis, students were already 
familiarised with the microscope and with microinstruments during the previous microanastomosis.

\section{Conclusions}

Our mini-course aroused substantial enthusiasm among all participants. In our country, surgery is unfortunately started late and practiced in autonomy mostly by aged surgeons after the achievement of permanent working positions. Residents are often frustrated by the lack of sufficient hands-on experience during training, and our data confirm the importance of investing in young, talented and motivated surgeons, since they can produce excellent performances. Since this course model is short-timed, cost-effective and highly reproducible, it could be introduced and implemented anywhere as a future educational prospect for preselecting young residents showing talent and natural predisposition and having ambitions towards microvascular reconstructive surgery.

\section{Acknowledgements}

This paper was awarded with the $3^{\text {rd }}$ SIO Price at the $104^{\text {th }}$ National Congress of the Italian Society for Otorhinolaryngology and Head and Neck Surgery, Sorrento 2017.

\section{References}

1 Carrel A. The operative technique of vascular anastomoses and the transplantation of viscera. Lyon Med 1902;98:859-63.

2. Carrel A, Guthrie CC. Functions of a transplanted kidney. Science 1905;22:473.
3 Carrel A, Guthrie CC. A new method for the homoplastic transplantation of the ovary. Science 1906;23:591.

4 Dohlman GF. Carl Olof Nylén and the birth of the otomicroscope and microsurgery. Arch Otolaryngol 1969;90:813-7.

5 Seidenberg B, Rosenak SS, Hurwitt ES, et al. Immediate reconstruction of the cervical esophagus by a revascularized isolated jejunal segment. Ann Surg 1959;149:162-71.

6 Goldstein M. Use of fresh human placenta for microsurgical training. J Microsurg 1979;1:70-1.

7 Mücke T, Borgmann A, Ritschl LM, et al. Microvascular training of medical students and surgeons - a comparative prospective study. J Craniomaxillofac Surg 2013;41:e187-90.

8 Chan WY, Figus A, Ekwobi C, et al. The 'round-the-clock' training model for assessment and warm up of microsurgical skills: a validation study. J Plast Reconstr Aesthet Surg 2010;63:1323-8.

9 Aoun SG, El Ahmadieh TY, El Tecle NE, et al. A pilot study to assess the construct and face validity of the Northwestern Objective Microanastomosis Assessment Tool. J Neurosurg 2015;123:103-9.

10 Blackwell KE, Brown MT, Gonzalez D. Overcoming the learning curve in microvascular head and neck reconstruction. Arch Otolaryngol Head Neck Surg 1997;123:1332-81.

11 Mathes SJ. Plastic Surgery. 2nd ed. Philadelphia: Elsevier; 2006. pp 507-538.

12 Khouri R. Avoiding free flap failure. Clin Plast Surg 1992;19:773-5.

13 Lascar I, Totir D, Cinca A, et al. Training program and learning curve in experimental microsurgery during the residency in plastic surgery. Microsurgery 2007;27:263-7.

Address for correspondence: Alberto Deganello, Unit of Otorhinolaryngology-Head and Neck Surgery, Department of Surgical Specialties, Radiological Sciences, and Public Health, University of Brescia, ASST Spedali Civili, piazzale Spedali Civili 1, 25123 Brescia, Italy. E-mail: adeganello@hotmail.com 